CENTRIFUGAL SLURRY PUMP

WEAR \& HYDRAULIC STUDIES

\author{
Quarterly Technical Progress Report \\ For The Period of \\ 1 April 1987 - 30 June 1987
}

Paul Cooper

\begin{abstract}
INGERSOLL-RAND COMPANY
942 Memorial Parkway

Phillipsburg, NJ 08865
\end{abstract}

Prepared For The

U. S. Department of Energy

Pittsburgh Energy Technology Center

Under Contract

DE-AC22-82PC50035

DISTRIBUTION OF THIS DOCUMENT IS UNLAMTED 


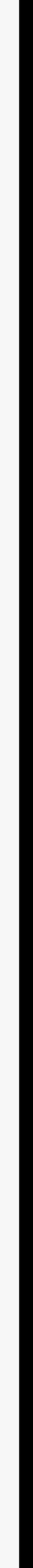




\section{DISCLAIMER NOTICE}

The following report was prepared as an account of work sponsored by the United States Government. Neither the employees, nor any contractors, subcontractors, or their employees make any warrant, expressed or implied, or assume any legal liability or responsibility for the accuracy, completeness, or usefulness of any information, apparatus, product, or process disclosed, or represent that its use would not infringe privately owned rights.

\section{DISCLAIMER}

This report was prepared as an account of work sponsored by an agency of the United States Government. Neither the United States Government nor any agency thereof, nor any of their employees, makes any warranty, express or implied, or assumes any legal liability or responsibility for the accuracy, completeness, or usefulness of any information, apparatus, product, or process disclosed, or represents that its use would not infringe privately owned rights. Reference herein to any specific commercial product, process, or service by trade name, trademark, manufacturer, or otherwise does not necessarily constitute or imply its endorsement, recommendation, or favoring by the United States Government or any agency thereof. The views and opinions of authors expressed herein do not necessarily state or reflect those of the United States Government or any agency thereof. 



\subsection{INTRODUCTION}

The following report marks the fourth quarter of the third phase of the centrifugal slurry pump improvement program. The program was begun in 1982 for the purpose of improving the operating life of centrifugal slurry pumps for coal liquefaction service. The first phase of the work reviewed pilot plant experience with centrifugal slurry pumps and identified, with the help of a literature search, the critical design parameters and materials required for such improvement. The second phase encompassed a) extensive small-scale testing of several hydraulic design concepts and b) testing and selection of materials - the results being incorporated in a prototype slurry pump design.

This third phase of the work has included i) prototype slurry pump testing against a state-of-the-art coal liquefaction slurry pump, wherein substantial reduction of wear was obtained at $60 \%$ higher speed at the same head and flow rate therefore at $60 \%$ higher specific speed - and ii) an investigation as to whether still higher specific speed is possible. The prototype pump tested in (i) had a specific speed of 600 . Another pump of this same design was re-fitted for investigation (ii) with a smaller impeller and associated liners so as to operate at a specific speed of 1000 . Table 1 contains the significant design features and operating conditions these two pumps.

Both the 600 and 1000 impellers and liners for this latter investigation (ii) were made of mild carbon steel to accelerate the testing time. The two pumps were run in series in the slurry test loop utilizing AFS \#110 sand ( $\approx 110$ mesh) at a concentration of 30 percent by weight in water at $80^{\circ} \mathrm{F}$.

As previously reported, twenty-four (24) hours of test time revealed a slightly lower overall wear rate for the 1000-specific-speed pump; however, excessive local wear occurred in the impeller eye area of that pump. This was attributed to too large a clearance between the pump-out vanes and the suction side of the volute liner. Wear elsewhere in the pump was uniform and comparable to that of the 600-specific-speed prototype pump.

\subsection{TECHNICAL PROGRESS}

During the current reporting period, the specific speed (Ns) comparison testing was completed, with a total of forty-eight (48) hours of test time having been accumulated. As in the first twenty-four (24) hours of this testing, both pumps operated at a suction pressure of 25 - 30 psig a head of $300 \mathrm{ft}$. at $260 \mathrm{gpm}$ on sand-water slurry with $30 \%$ sand by weight. The higher speed pump had $61 \%$ efficiency at $300 \mathrm{gpm}$ in clear water vs $46 \%$ for the $600-\mathrm{Ns}$ pump.

The soft steel impellers and liners wore quickly (as desired) and uniformly vs time during the test. Table 2 contains the wejght loss hist.ory expressed in percent of the original weight 

of the associated component. This table shows that there was less total wear on the 1000-Ns pump; however, Set 3 of the accompanying photographs show that this pump suffered highly localized wear and actual perforation of the blades at the impeller eye. Examination of Sets 1 and 2 of the photographs reveals that other areas of the 1000-Ns pump fared better - in fact possibly better than did the 600-Ns pump.

The backside liner of the 600-Ns pump had a design flow in which the bolt heads were exposed to active slurry recirculation behind the impeller. This was corrected in the 1000-Ns design. It is likely that both pumps would have performed similarly in this regard had the $600-\mathrm{Ns}$ backside liner also been corrected.

The severe eye wear of the 1000-Ns pump is attributed to excessive leakage between the suction-side of the volute liner and the impeller pump-out vanes. This is believed to be the consequence of a larger clearance about 0.130 inch (instead of 0.030 to 0.060 inch as planned) between these two elements (which also experienced excessive localized wear) and was caused by a machining error. On the other hand, almost no wear occurred on the other side of the impeller, where the backside liner also faces impeller pump-out vanes. Zero leakage occurs through this clearance (which was about 0.060 inch). Thus, if the suction side clearance had been 0.030 to 0.060 inch as planned; the pump-out vanes would have restricted the leakage more, leaving reason to believe that much less wear would have occurred in the impeller eye region. The 1000-Ns pump would then have been more nearly equal to the $600-\mathrm{Ns}$ pump in terms of wear.

With this completion of the specific speed effects testing, all work on this program has been completed except for the final report.

\subsection{CONCLUSIONS}

Since the higher speed pump experienced more localized wear in the eye region, it is easy to conclude that this machine exceeded the practical limit for blade speed in this region. However, improper clearance is undoubtedly the cause of this poor result. In all other respects except for those directly associated with this clearance, the 1000-specific-speed pump performed as well as or better than the 600-specific speed pump in terms of wear.

The higher speed machine also had over ten (10) points more efficiency than the lower speed pump. This fact, together with the above analysis, leads us to the tentative conclusion that full-scale coal liquefaction plants can indeed benefit from the smaller pumps that would be obtained at 1000 . specific speed (or 

more) than would result if the lower specific speeds of this study and of the pilot plants (still lower) were used. These benefits are higher efficiency and wear rates that do not exceed those of lower specific speed pumps containing the same hydraulic improvements that were proven in the earlier testing of this program.

TABLE 1

Design Features and Operating Conditions of Slurry Pumps Used in Specific Speed Investigation

Original Prototype

Specific Speed

Design Flow Rate, GPM

Head, Ft. (in water at above flow rate)

Flow Rate When Operating On SIurry

(30\% sand; Density $=75 \mathrm{Ibm} / \mathrm{ft}^{3}$, GPM

Head at Slurry Flow Rate, ft.

Speed, RPM

Impeller Diameter, in.

Ratio of Cutwater Diameter

To Impeller Diameter

Impeller Exit Tip Speed, ft/sec

Impeller Inlet Absolute Velocity,ft/sec
600

300

320

260

260

300

300

2700

4500

11.25

7.00

1.46

1.34

133

137

36 


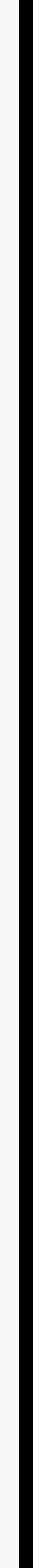




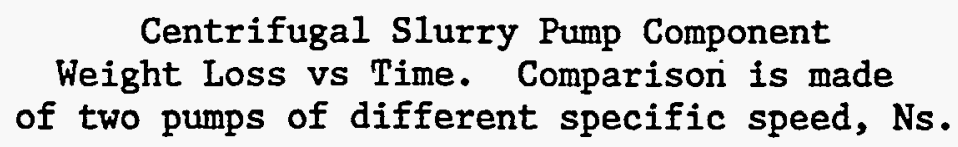

Cumulative Weight Loss, \%

Component

600-Ns Pump

1000-Ns Pump

1. 24 Hours

Impeller

4.4

7.8

Suction Liner

3.4

2.0

Main (Volute) Liner

4.0

2.4

Backside Liner

8.1

5.1

Total

19.9

17.3

2. 48 Hours

Impeller

7.8

17.6

Suction Liner

4.0

2.4

Main (Volute) Liner

8.3

3.8

Backside Liner

16.3

9.2

Total (Cumulative)

36.4

33.0

PC22887:e1b. 


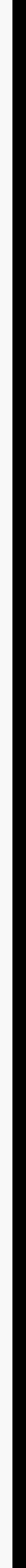


Photographs of Carbon Steel Pump Internals After 48

Hours of Testing in 30\% Sand-Water Slurry. (Flow Rate Was 260 GPM and Head Was $300 \mathrm{ft}$. per Pump.)
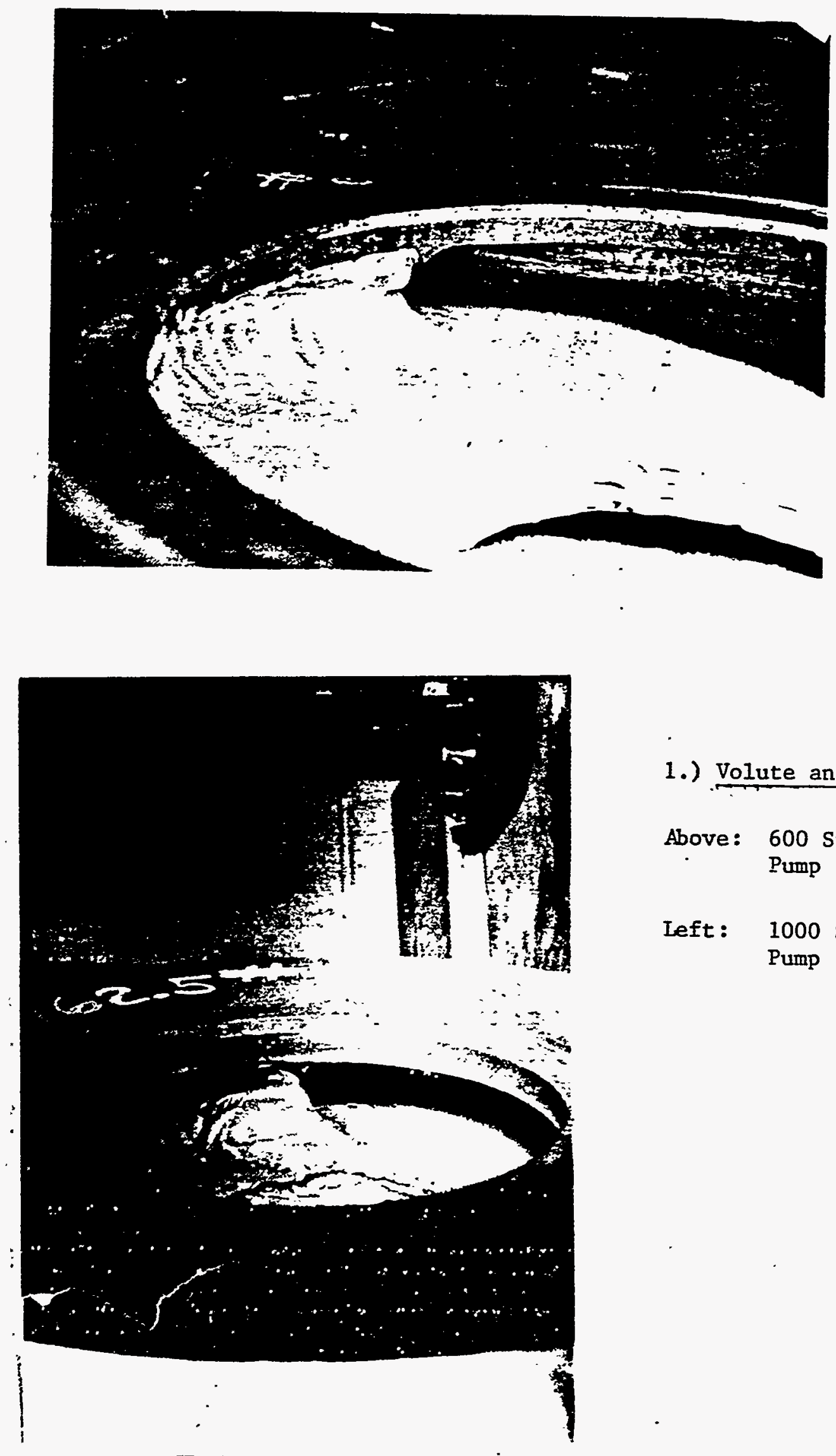

1.) Volute and Cutwater

Above: 600 Specific Speed Pump

Left: 1000 Specific Speed 


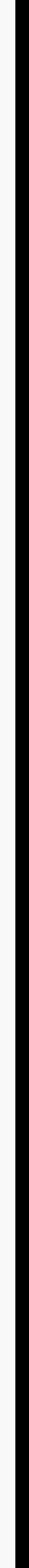


Photographs After 48 Hours of Testing (Continued)
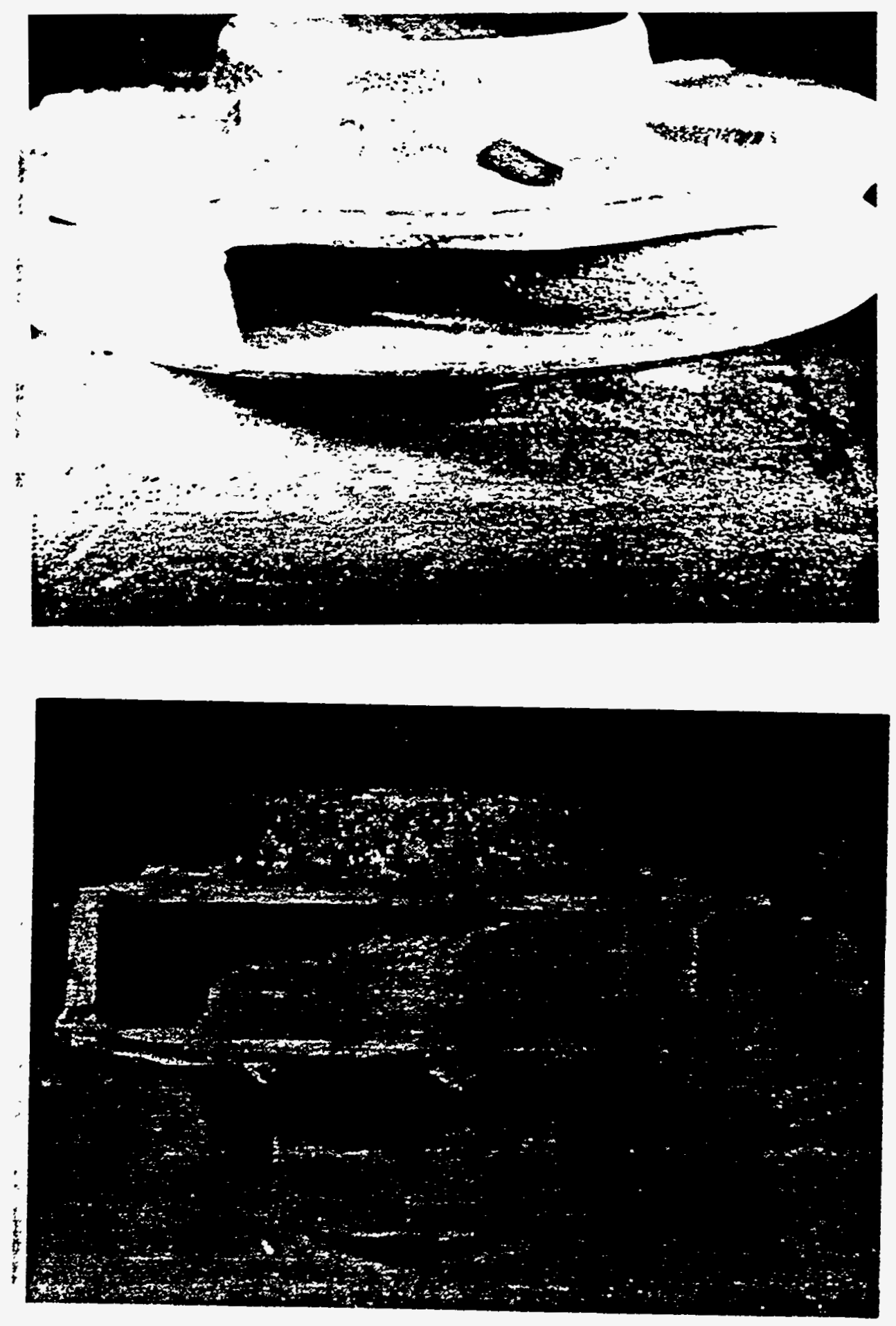

2.) Impeller Exit

Top: 600 Specific Speed Pump

Bottom: 1000 Specific Speed Pump 

Photographs After 48 Hours of Testing (Continued)
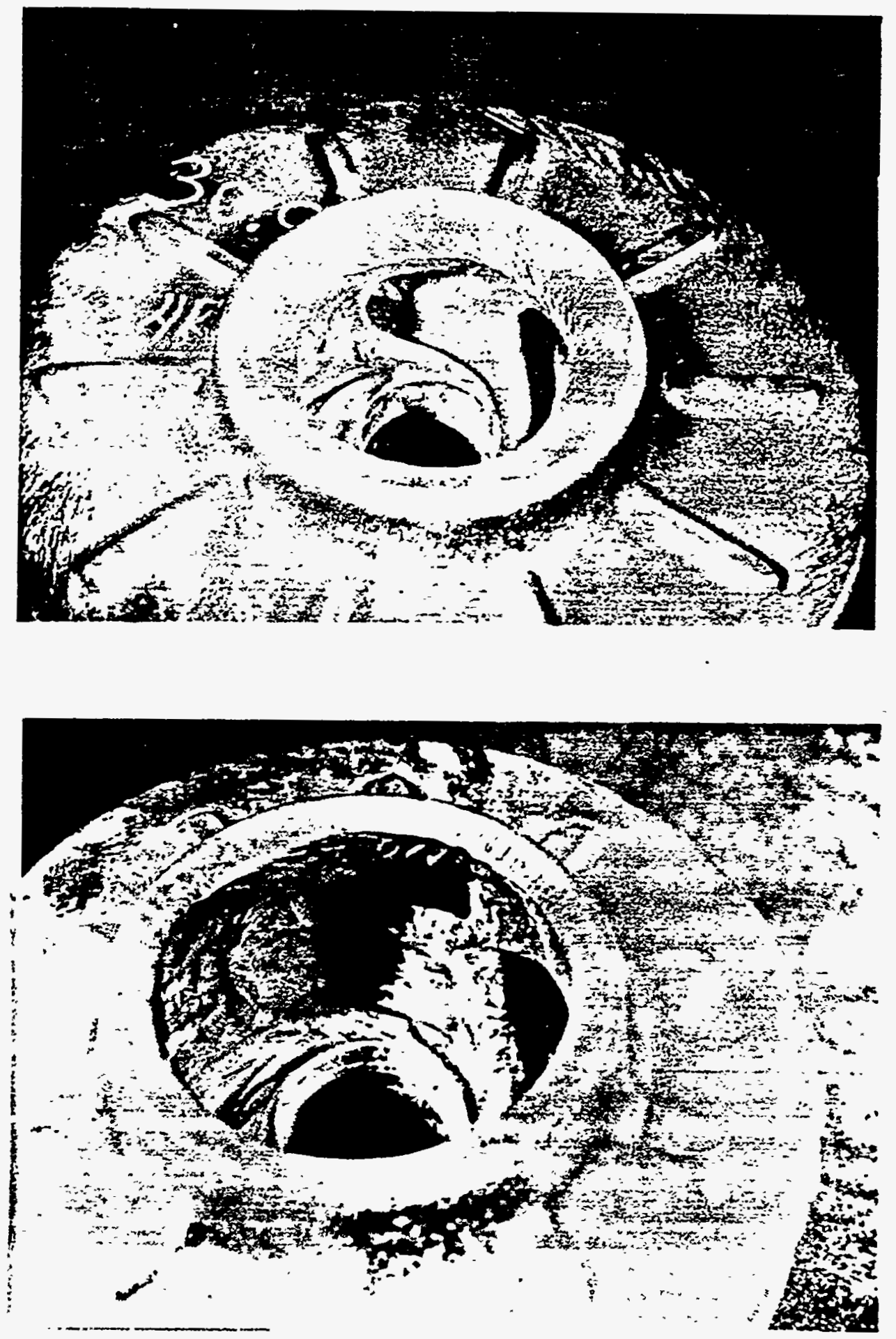

3.) Impe1ler Eye

Top: 600 Specific Speed Pump

Bottom: 1000 Spectf $1 c$ Speed Pump 
